\title{
Topical atenolol versus pilocarpine: a double-blind study of the effect on ocular tension
}

\author{
K. WETTRELL, K. WILKE, AND M. PANDOLFI \\ From the Department of Ophthalmology, Hospital of Malmö, University of Lund, Malmö, and \\ Department of Experimental Ophthalmology, University Eye Clinic, Lund, Sweden
}

SUMMARY Topical atenolol (a $\beta_{1}$-adrenoceptive antagonist), pilocarpine, and placebo were tested in a randomised double-blind crossover trial of 8 patients with ocular hypertension. Atenolol $(2 \%$ 3 times a day) caused a fall in intraocular pressure (IOP) comparable to that achieved by topical application of pilocarpine ( $2 \% 3$ times a day). The decrease in IOP by each compound was demonstrable on the second day of application and was significantly $(P<0.05)$ reduced on the seventh and 14th days of treatment. The combination of $2 \%$ pilocarpine and $2 \%$ atenolol administered 15 minutes apart ( 3 times a day) lowered the IOP significantly from the second day of treatment, and this reduction persisted throughout the trial period of 14 days. This combined treatment lowered the IOP more than either substance alone. However, this further decrease was statistically significant only on the 14th day of treatment (atenolol versus atenolol + pilocarpine, $\mathrm{P}<0 \cdot 05$ ).

No change of the episcleral venous pressure was observed after 14 days' treatment with either atenolol or pilocarpine alone, or combined.

Atenolol (Tenormin) is a cardioselective $\left(\beta_{1}\right)$ adrenoceptive antagonist devoid of intrinsic sympathomimetic activity and membrane-stabilising properties (Barret et al., 1973). Systemic administration has been reported to reduce the IOP both in healthy volunteers and in patients with increased IOP (Elliot et al., 1975; Wettrell and Pandolfi, 1975; Macdonald et al., 1976, 1977; Wettrell et al., 1977). It has recently become available for local application. In short-term studies atenolol eye drops have been found to reduce the IOP both in normal eyes and in eyes with elevated IOP (Phillips et al., 1976, 1977; Wettrell and Pandolfi, 1977).

The mechanism by which these drugs exert their effect on the IOP is not yet clear. It may perhaps be by altering the intravascular pressure in the recipient episcleral veins (Prv.) In a recent study (Wettrell et al., 1977) systemic administration of propranolol, practolol, or atenolol had no demonstrable effect on the Prv. However, whether topical application of $\beta$-antagonists can have any such effect is unknown.

The purpose of the present investigation was thus

Address for reprints: Dr Karin Wettrell, Department of Ophthalmology, Hospital of Malmö, University of Lund, S-214 01 Malmö, Sweden twofold, namely, to compare the effect, if any, of topical atenolol on IOP with that of pilocarpine, and, secondly, to study the two drugs separately and combined for any effect on the Prv.

\section{Material}

PATIENTS

Eight patients, 2 males and 6 females (16 eyes), with intraocular hypertension (untreated IOP $\geqslant$ $22 \mathrm{mmHg}$ ) were selected for the investigation. They were aged 43 to 77 (mean 64), and had normal visual fields and no demonstrable glaucomatous involvement of the optic discs. Six patients had previously been treated with pilocarpine, which was withdrawn at least 48 hours before the trial. The patients did not receive any adrenergic drugs during the trial and had no history of asthma, bronchospasm, cardiac failure, or other disorders contraindicating administration of $\beta$-adrenoceptive blocking compounds.

DRUGS

Atenolol eye drops, prepared by ICI Pharmaceuticals, contained $2 \%$ of the substance. Benzalkonium chloride $(0.02 \% \mathrm{v} / \mathrm{v})$ was used as a preservative, and the $\mathrm{pH}$ was adjusted to $6 \cdot 0$. Control 
drops had the same composition except for the absence of atenolol. Pilocarpine eye drops were prepared by the local pharmacy of the Hospital of Malmö and contained pilocarpine chloride $2 \%$, methylhydroxybenzoate $0.04 \%$, propylhydroxybenzoate $0.02 \%$, and saline. Control drops had the same composition but lacked pilocarpine.

\section{Methods}

\section{ADMINISTRATION}

The trial was performed in a double-blind crossover manner. The patients were instructed to apply the eye drops ( 1 drop in each eye) from 2 coded bottles with an interval of 15 minutes at 7 a.m., 1 p.m., and 7 p.m. on 14 consecutive days. Each patient received atenolol + pilocarpine placebo, pilocarpine + atenolol placebo, atenolol + pilocarpine and atenolol placebo + pilocarpine placebo in randomised order. The drug-free interval between 2 consecutive trial periods was always at least $\mathbf{4 8}$ hours.

\section{IOP REGISTRATION}

IOP was measured with the Goldmann applanation tonometer at 8 a.m., noon, and 4 p.m. on the day before treatment was started. Before tonometry 1 to 2 drops of Fluress, a combination of oxibuprocaine hydrochloride and sodium fluorescein, were instilled into the conjunctival sac. The tonometer was calibrated daily. The measurements were repeated on the 14th day of each period of treatment. On the second and seventh day of administration IOP was recorded also at noon.

\section{EPISCLERAL VENOUS PRESSURE}

The episcleral venous pressure (Prv.) was studied by the method described by Krakau et al. (1973). In this method the actual vessel is compressed by a jet of air whose pressure is increased until the vessel is occluded (that is +++ effect). The results are given in $\mathrm{mmHg}$.

The measurements were made either on a so-called recipient vein, that is, an episcleral vein which had just received a large aqueous vein, or on an ordinary episcleral vein. In a given eye the measurements were always made on the same vessel. Three consecutive values of +++ were measured. All recordings were made on sitting patients after application of 1 to 2 drops of oxibuprocaine hydrochloride $0.4 \%$. The Prv. was recorded the day before treatment and on the 14th day of application in each period of treatment. The pressure was always measured at the same time of day (around 2 p.m.). The actual venous pressure is about 3 to $4 \mathrm{mmHg}$ lower than the value of the +++ effect (Krakau et al., 1973).
STATISTICAL ANALYSIS

The mean IOP for all patients during treatment with the various combinations of the drugs were tested statistically with Student's $t$ test for paired data. The recordings made during treatment with placebo and with the active substance were compared. The same procedure was used in the statistical treatment of the Prv. values.

\section{Results}

INTRAOCULAR PRESSURE (IOP)

Application of pilocarpine lowered the IOP to roughly the same extent as atenolol (Tables 1, 2, and Fig. 1). This decrease was demonstrable on the second day of treatment and was statistically significant $(P<0.05)$ from the seventh day and remained so throughout the rest of the treatment period. Although the effect of each drug was still obvious on the 14th day of treatment (Table 2 and Fig. 1), it was only the recordings at noon that were significantly $(P<0.05)$ decreased.

Combined administration of pilocarpine and atenolol significantly lowered the IOP from the second day of treatment and throughout the rest of

Table 1 Mean variation in mean IOP values at noon ( $\mathrm{mmHg}) \pm S E M$ of 8 patients during treatment with pilocarpine, atenolol, and pilocarpine + atenolol (active substance compared with placebo). Statistical significance expressed as $*(P<0.05),+(P<0.01)$

\begin{tabular}{lllll}
\hline Substance & $\begin{array}{l}\text { No. of } \\
\text { patients }\end{array}$ & Day 2 & Day 7 & Day 14 \\
\hline Pilocarpine & 8 & $-1.5 \pm 1.03$ & $-2.1 \pm 0.75 *$ & $-2.3 \pm 0.88 *$ \\
Atenolol & 8 & $-1.4 \pm 1.45$ & $-2.9 \pm 1.03 *$ & $-1.6 \pm 0.56 *$ \\
$\begin{array}{l}\text { Pilocarpine }+ \\
\text { atenolol }\end{array}$ & 8 & $-3.3 \pm 1.35 *$ & $-3.8 \pm 1.21 *$ & $-3.3 \pm 0.80 \dagger$ \\
\hline
\end{tabular}

Table 2 Mean IOP $(\mathrm{mmHg}) \pm S E M$ of 8 patients after 14 days' treatment with placebo, pilocarpine, atenolol, and pilocarpine + atenolol (active substance compared with placebo). Statistical significance expressed as $*(P<0.05)$ and $+(P<0.01)$

\begin{tabular}{lllll}
\hline Substance & $\begin{array}{l}\text { No. of } \\
\text { patients }\end{array}$ & 8 a.m. & Noon & 4 p.m. \\
\hline Untreated & 8 & $26.1 \pm 0.88$ & $24.5 \pm 1.06$ & $23.6 \pm 1.22$ \\
Placebo & 8 & $24.5 \pm 1.5$ & $24.2 \pm 0.94$ & $23.4 \pm 1.08$ \\
Pilocarpine & 8 & $22.6 \pm 0.89$ & $21.9 \pm 0.90^{*}$ & $21.7 \pm 1.21$ \\
$\begin{array}{l}\text { Atenolol } \\
\begin{array}{c}\text { Pilocarpine }+ \\
\text { atenolol }\end{array}\end{array}$ & 8 & $22.4 \pm 0.65$ & $22.6 \pm 0.60 *$ & $22.4 \pm 1.20$ \\
\hline
\end{tabular}




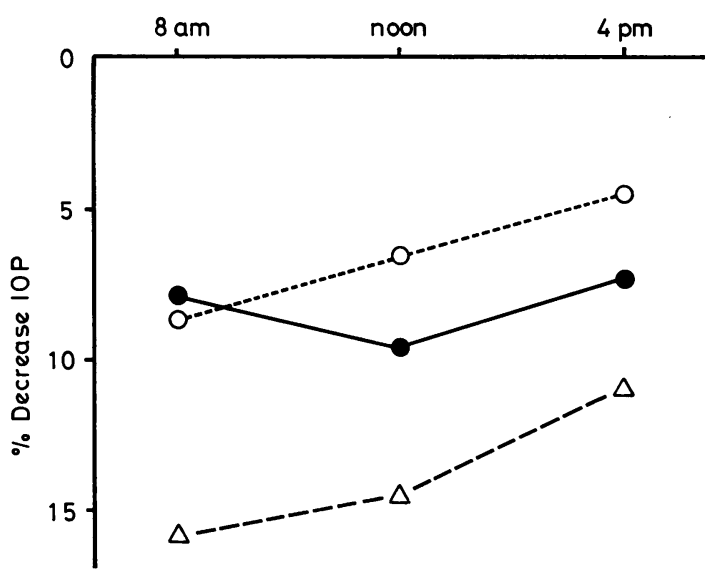

Fig. 1 IOP decrease in per cent after 14 days' treatment with pilocarpine, atenolol, and pilocarpine + atenolol (active substance compared with placebo)

Pilocarpine ( - $)$, atenolol $(\mathrm{O}-\mathrm{O})$, pilocarpine + atenolol $(\Delta-\Delta)$

the trial (Tables 1, 2, and Fig. 1). On the 14th day combined pilocarpine and atenolol caused a statistically significant reduction of IOP throughout the day $(P<0.05$ to $P<0.01)$ (Table 2 and Fig. 1). Combined pilocarpine and atenolol lowered the IOP more than either substance alone, though the difference was not statistically significant with one exception (atenolol compared with atenolol + pilocarpine on the 14th day of treatment).

EPISCLERAL VENOUS PRESSURE

After 14 days' treatment neither pilocarpine nor atenolol separately or combined had any demonstrable effect on the episcleral venous pressure (Table 3).

\section{SIDE EFFECTS}

One patient reported headache and smarting pain during the initial treatment with pilocarpine. Combined atenolol and pilocarpine caused itching and discomfort of the eyes of 2 patients. However, these disturbances were only moderate and not such as to prevent completion of the trial. Examination

Table 3 Mean episcleral venous pressure $(+++)$ expressed in $\mathrm{mmHg} \pm S E M$ after 14 days' treatment with placebo, pilocarpine, atenolol, and pilocarpine + atenolol (active substance compared with placebo)

\begin{tabular}{llllll}
\hline $\begin{array}{l}\text { No. of } \\
\text { patients }\end{array}$ & Untreated & Placebo & Pilocarpine & Atenolol & $\begin{array}{l}\text { Pilocarpine }+ \\
\text { atenolol }\end{array}$ \\
\hline 8 & $16.5 \pm 0.96$ & $16.4 \pm 1.03$ & $16.2 \pm 0.86 *$ & $15.9 \pm 0.85$ & $16.0 \pm 0.91$ \\
& & NS & NS & NS \\
\hline 7 patients & & & &
\end{tabular}

of the eyes revealed nothing remarkable. No consistent changes in refraction were observed.

\section{Discussion}

In this study topical atenolol (2\% 3 times a day) reduced the IOP to about the same extent as pilocarpine ( $2 \% 3$ times a day) in patients with ocular hypertension. This is in agreement with previous reports of the hypotensive effect of topical application of other $\beta$-adrenoceptive inhibitors (Bucci et al., 1968; Vale et al., 1972; Vale and Phillips, 1973; Bonomi and Steindler, 1975; Katz et al., 1976; Bucci, 1976; Krieglstein et al., 1977; Zimmerman and Kaufman, 1977a, b). The hypotensive effect of topical atenolol has also been demonstrated in healthy volunteers and patients with raised IOP (Phillips et al., 1976, 1977; Wettrell and Pandolfi, 1977). No reports were available until now on the IOP-decreasing effect of atenolol compared to that of pilocarpine.

The IOP decrease was demonstrable for both drugs on the second day of treatment and was statistically significant from the seventh day of treatment, persisting throughout the rest of the 14-day trial. The decrease in IOP observed during treatment with $2 \%$ atenolol is in fair agreement with that reported by Wettrell and Pandolfi (1977). In that study a larger reduction was observed on the first day of treatment, which, however, gradually diminished to become comparable to the reduction observed in the present investigation. A tendency to tachyphylaxis has also been noted for bupranolol (Krieglstein et al., 1977).

Although the 2 drugs reduced the IOP to roughly the same extent, they are believed to differ in their mode of action. Thus, pilocarpine is generally believed to facilitate the outflow of aqueous humour (see Gaasterland et al., 1975), while systemic administration of $\beta$-blocking agents (Macdonald $e t$ al., 1976) are thought to reduce the production of aqueous humour. A decreased flow has also been suggested to be the main cause of the fall in IOP following topically applied pindolol (Bonomi and Steindler, 1975). In accordance with a previous investigation of systemic atenolol (Wettrell et al., 1977) no influence on the episcleral venous pressure was observed after 14 days' treatment with topical atenolol alone or combined with pilocarpine. This rules out the possibility that alterations in the recipient episcleral veins are responsible for the decrease in IOP. Neither did pilocarpine applied separately for a fortnight have any effect on the episcleral venous pressure, although Wilke (1974) reported an early rise in Prv. after application of $2 \%$ pilocarpine. 
Combined atenolol and pilocarpine lowered the IOP more than either drug alone. This is in agreement with Bietti's (1972) finding of an additive effect of topical application of propranolol and pilocarpine. The additive effect of combined pilocarpine and atenolol argues against the hypothesis proposed by Phillips et al. (1977) that pilocarpine may reduce the effect of atenolol by causing contraction of the ciliary muscle and thereby prevent the penetration of topical atenolol into the ciliary processes.

According to Macdonald et al. (1976) systemic atenolol is more effective than propranolol in reducing IOP. One might expect this to hold also for topical application of the compounds. This may make topical atenolol (which furthermore lacks anaesthetic properties) more useful in clinical practice.

We thank Dr Pål Stenberg for advice and Miss Ulla Andersson for technical assistance.

The study was supported by grants from the Medical Faculty of Lund University and Thorsten and Elsa Segerfalk's Foundation.

Atenolol eye drops were kindly supplied by ICIPharma, Gothenburg, Sweden.

\section{References}

Barret, A. M., Carter, J., Fitzgerald, J. D., Hull, R., and Le Count, D. (1973). A new type of cardioselective adrenoceptive blocking drug. British Journal of Pharmacology, 48, $340 \mathrm{P}$.

Bietti, G. (1972). Recent experimental, clinical and therapeutic research on the problems of intraocular pressure and glaucoma. American Journal of Ophthalmology, 73, 475-500.

Bonomi, L., and Steindler, P. (1975). Effect of pindolol on intraocular pressure. British Journal of Ophthalmology, 59, 301-303.

Bucci, M. G., Missiroli, A., Giraldi, J. P., and Virno, M. (1968). La somministrazione locale del propranololo nella terapia del glaucoma. Bollettino d' Oculistica, 47, 51-60.

Bucci, M. G. (1976). La somministrazione locale dell' oxprenololo (beta-bloccante) nella terapia del glaucoma. Nota preliminare. Bollettino d' Oculistica, 54, 235-242.

Elliot, M. J., Cullen, P. M., and Phillips, C. I. (1975). Ocular hypotensive effect of atenolol (Tenormin ICI). A new beta-adrenergic blocker. British Journal of Ophthalmology, 59, 296-300.
Gaasterland, D., Kupfer, C., and Ross, K. (1975). Studies of aqueous humor dynamics in man IV. Effects of pilocarpine upon measurements in young normal volunteers. Investigative Ophthalmology, 14, 848-853.

Katz, I. M., Hubbard, W. A., Getson, A. J., and Gould, A. L. (1976). Intraocular pressure decrease in normal volunteers following timolol ophthalmic solution. Investigative Ophthalmology, 15, 489-492.

Krakau, C. E. T., Widakowich, J., and Wilke, K. (1973). Measurements of the episcleral venous pressure by means of an air jet. Acta Ophthalmologica, 51, 185-196.

Krieglstein, G. K., Sold-Darseff, J., and Leydhecker, W. (1977). The intraocular pressure response of glaucomatous eyes to topically applied bupranolol. A pilot study. Albrecht von Graefes Archiv für klinische und experimentelle Ophthalmologie, 202, 81-86.

Macdonald, M. J., Cullen, P. M., and Phillips, C. I. (1976). Atenolol versus propranolol. A comparison of ocular hypotensive effect of an oral dose. British Journal of Ophthalmology, 60, 789-791.

Macdonald, M. J., Gore, S. M., Cullen, P. M., and Phillips, C. I. (1977). Comparison of ocular hypotensive effects of acetazolamide and atenolol. British Journal of Ophthalmology, 61, 345-348.

Phillips, C. I., Macdonald, M., Gore, S. M., and Cullen, P. M. (1976). Atenolol eye drops. British Medical Journal, 2,1448 .

Phillips, C. I., Gore, S. M., Macdonald, M. J., and Cullen, P. M. (1977). Atenolol eye drops in glaucoma: a doublemasked controlled study. British Journal of Ophthalmology, 61, 349-353.

Vale, J., Gibbs, A. C. C., and Phillips, C. I. (1972). Topical propranolol and ocular tension in the human. British Journal of Ophthalmology, 56, 770-775.

Vale, J., and Phillips, C. I. (1973). Practolol (Eraldin) eye drops as an ocular hypotensive agent. British Journal of Ophthalmology, 57, 210-214.

Wettrell, K., and Pandolfi, M. (1975). Effect of oral administration of various beta-blocking agents on the intraocular pressure in healthy volunteers. Experimental Eye Research, 21, 451-456.

Wettrell, K., and Pandolfi, M. (1977). Effect of topical atenolol on intraocular pressure. British Journal of Ophthalmology, 61, 334-338.

Wettrell, K., Wilke, K., and Pandolfi, M. (1977). Effect of beta-adrenergic agonists and antagonists on repeated tonometry and episcleral venous pressure. Experimental Eye Research, 24, 613-619.

Wilke, K. (1974). Early effects of epinephrine and pilocarpine on the intraocular pressure and the episcleral venous pressure in the normal human eye. Acta Ophthalmologica, 52, 231-241.

Zimmerman, T. J., and Kaufman, H. E. (1977a). Timolol: a $\beta$-adrenergic blocking agent for the treatment of glaucoma. Archives of Ophthalmology, 95, 601-604.

Zimmerman, T. J., and Kaufman, H. E. (1977b). Timolol: dose response and duration of action. Archives of Ophthalmology, 95, 605-607. 